\title{
$\beta$-elemonic acid inhibits the cell proliferation of human lung adenocarcinoma A549 cells: The role of MAPK, ROS activation and glutathione depletion
}

\author{
TSU-TUAN WU ${ }^{1,2}$, CHIEN-LIN LU ${ }^{3}$, HEN-I LIN ${ }^{4,5}$, BING-FANG CHEN ${ }^{4}$ and GUEY-MEI JOW ${ }^{4}$ \\ ${ }^{1}$ Department of Respiratory Therapy, Fu Jen Catholic University, New Taipei City; ${ }^{2}$ Department of Internal Medicine, \\ Taipei County Hospital, New Taipei City; ${ }^{3}$ Division of Nephrology, Department of Medicine, \\ Shin-Kong Wu Ho-Su Memorial Hospital, Taipei; ${ }^{4}$ School of Medicine, Fu Jen Catholic University, New Taipei City; \\ ${ }^{5}$ Department of Internal Medicine, Catholic Cardinal Tien Hospital, New Taipei City, Taiwan, R.O.C.
}

Received July 24, 2015; Accepted September 17, 2015

DOI: $10.3892 /$ or.2015.4368

\begin{abstract}
. $\beta$-elemonic acid, a known triterpene, exhibits anti-inflammatory effects, yet research on the pharmacological effects of $\beta$-elemonic acid is rare. We investigated the anticancer effects and the related molecular mechanisms of $\beta$-elemonic acid on human non-small cell lung cancer (NSCLC) A549 cells. The effects of $\beta$-elemonic acid on the growth of A549 cells were studied using a 3-(4,5)-2,5-diphenyltetrazolium bromide (MTT) assay. Apoptosis was detected using Annexin V staining. The effect of $\beta$-elemonic acid on the cell cycle of A549 cells was assessed using the propidium iodide method. The change in reactive oxygen species (ROS) was detected using a dichlorodihydrofluorescein diacetate (DCFH-DA) assay with microscopic examination. The expression levels of $\mathrm{Bcl}-2$ family proteins, mitogen-activated protein kinase (MAPK) family proteins and cyclooxygenase 2 (COX-2) were detected using western blot analysis. Our data revealed that $\beta$-elemonic acid strongly induced human A549 lung cancer cell death in a dose- and time-dependent manner as determined by the MTT assay. $\beta$-elemonic acid-induced cell death was considered to be apoptotic when the phosphatidylserine exposure was observed using Annexin V staining. The death of human A549 lung cancer cells was caused by apoptosis induced by activation of ROS activity, increase in the sub-G1 proportion, downregulation of Bcl-2 expression, upregulation of Bax expression and inhibition of the MAPK signaling pathways. These results clearly demonstrated that $\beta$-elemonic acid inhibits proliferation by
\end{abstract}

Correspondence to: Dr Guey-Mei Jow, School of Medicine, Fu Jen Catholic University, 510 Zhongzheng Road, Xinzhuang, New Taipei City 24205, Taiwan, R.O.C.

E-mail: 039666@mail.fju.edu.tw

Key words: $\beta$-elemonic acid, apoptosis, reactive oxygen species, mitogen-activated protein kinases, glutathione depletion inducing hypoploid cells and cell apoptosis. Moreover, the anticancer effects of $\beta$-elemonic acid were related to the MAPK signaling pathway, ROS activation and glutathione depletion in human A549 lung cancer cells.

\section{Introduction}

Cancer is a major public health issue worldwide because of its substantially high rates of morbidity and mortality. Lung cancer is currently the second most common cause of cancerrelated deaths in Taiwan (1). More than $75 \%$ of lung cancers are diagnosed as non-small cell lung cancers (NSCLC). Chemotherapy is always the first choice for NSCLC patients who have a positive performance status. An appropriate chemotherapy regimen can significantly remit clinical symptoms and improve the quality of life of patients with advanced NSCLC. However, with currently available chemotherapeutics, only a modest increase in the five-year survival rate can be achieved in patients with advanced NSCLC $(2,3)$. Thus, enhanced chemotherapeutics are required to improve the five-year survival rate.

Numerous cytotoxic chemicals, including anticancer drugs, cause cell death in sensitive cells by inducing apoptosis, at least partially (4). The two major cellular routes involved in cytotoxic chemical-induced apoptosis have been identified: namely, the death receptor pathway and the mitochondrial pathway (5). In the death receptor pathway, the binding of death receptors with ligands, such as Fas or cross-linking antibodies, results in receptor trimerization. This is followed by the binding of the adaptor molecule, the Fas-associated death domain, to the cytoplasmic domain of the receptor. Subsequent activation of the caspase- 3 family includes several effectors and pro-caspases in the caspase cascade (6). In addition, the mitochondrial pathway relies on the release of cytochrome $c$ from the mitochondria into the cytosol. This process is initiated by the interaction of the mitochondria with one or more of the Bcl-2 family proteins. Thus, numerous Bcl-2 family proteins have been considered to be the major regulators of the apoptotic process, and represent a critical checkpoint within apoptotic pathways, acting 
upstream of such irreversible damage to cellular constituents (7). The Bcl-2 family of homologous proteins comprises pro-apoptotic and anti-apoptotic molecules (8). For instance, $\mathrm{Bcl}-2$ and $\mathrm{Bcl}-\mathrm{X}_{\mathrm{L}}$ have been demonstrated to inhibit apoptosis, whereas Bad, Bak and Bax have been reported to enhance apoptosis $(9,10)$. Their anti-apoptotic or pro-apoptotic functions rely on constituting the heterodimers (7). Furthermore, the ratio of anti-apoptotic to pro-apoptotic proteins also partially determines how a cell responds to apoptotic or survival signals (11). In certain human cancer cell lines, the expression levels of $\mathrm{Bcl}-2$ and $\mathrm{Bcl}-\mathrm{X}_{\mathrm{L}}$ result in a positive correlation with the prevention of apoptosis induced by various cytotoxic drugs (12). However, overexpression of the Bax protein sensitizes cancer cells to several chemotherapeutic agents resulting in enhanced apoptosis (12). These observations suggest that modulation of intrinsic targets, such as Bcl-family proteins, can be a potential strategy for developing anticancer agents.

Cyclooxygenase (COX)-2 is a crucial rate-limiting enzyme involved in inflammatory processes because of its role in producing prostaglandins from arachidonic acid. COX-2 is a downstream target of PPAR $\gamma$, and PPAR $\gamma$ ligands have been shown to induce COX-2 expression in mammary epithelial cells (13), monocytes (14) and human synovial fibroblasts (15). Unlike COX-1, which is the constitutive housekeeping isoform, COX-2 is an inducible isoform that can be upregulated by growth factors, cytokines and lipopolysaccharides in a wide variety of cells (16). Tumor necrosis factor $\alpha$ (TNF $\alpha$ ) is a pleiotropic cytokine that plays a critical role in numerous biological effects, including inflammation, by inducing the production of cytokines and pro-inflammatory mediators such as COX-2. Previous studies have shown that TNF $\alpha$ can induce NF- $\mathrm{kB}$ dependent COX-2 expression in A549 cells $(16,17)$. ROS have been demonstrated to activate several mitogen-activated protein serine/threonine kinases (MAPKs) that transduce diverse extracellular stimuli (mitogenic growth factors, environmental stresses and pro-apoptotic agents) to the nucleus through kinase cascades to regulate a wide array of cellular processes, including proliferation, differentiation and apoptosis (18-20).

$\beta$-elemonic acid $(13 \alpha, 14 \beta, 17 \alpha, 20 \mathrm{~S},-3$-Oxolanosta- 8 , 24-dien-21-oic acid) is a known triterpene that has not yet been used in therapy or investigated for its pharmaceutical effects (21). Few studies have demonstrated the anti-inflammatory activities of $\beta$-elemonic acid (22). Despite extensive analysis of the antitumor activities of $\beta$-elemonic acid, its ability to modulate lung cancer growth has not been effectively characterized. In the present investigation, we studied the quantitative and qualitative changes of several known effectors in the $\beta$-elemonic acid-induced apoptotic process in human NSCLC A549 cells.

\section{Materials and methods}

Materials and cell culture. $\beta$-elemonic acid (Fig. 1) was obtained from Sigma-Aldrich (St. Louis, MO, USA), and it was dissolved in pure grade dimethyl sulfoxide (DMSO). Human NSCLC A549 cells were obtained from the American Type Culture Collection (ATTC; Manassas, VA, USA). Annexin V/propidium iodide (PI) apoptosis detection kits

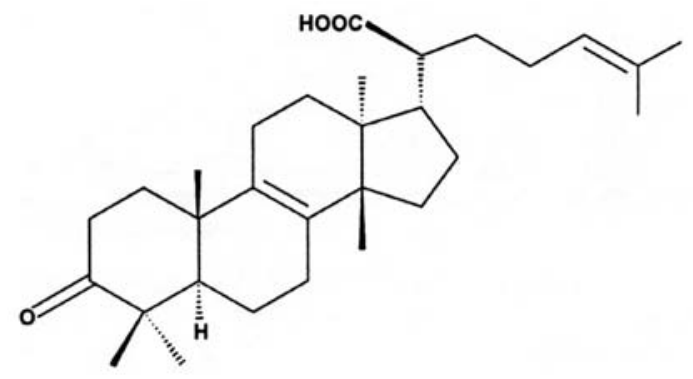

Figure 1. Chemical structure of $\beta$-elemonic acid.

were purchased from R\&D systems (Minneapolis, MN, USA). Monoclonal antibodies for $\mathrm{p}-\mathrm{Bcl}-2, \mathrm{Bcl}-\mathrm{X}_{\mathrm{L}}$, Bax, MAPK family, COX-2 and anti-rabbit IgGs were purchased from Cell Signaling Technology, Inc. (Danvers, MA, USA). All chemicals were of the highest pure grade available.

Human NSCLC A549 cells were maintained in Dulbecco's modified Eagle's medium (DMEM), supplemented with heat inactivated $10 \%$ fetal bovine serum (FBS), $100 \mu \mathrm{g} / \mathrm{ml}$ of penicillin, $100 \mu \mathrm{g} / \mathrm{ml}$ of streptomycin and $100 \mu \mathrm{g} / \mathrm{ml}$ of amphotericin B (all from Hyclone, Logan, UT, USA). The cells were grown in a humidified incubator at $37^{\circ} \mathrm{C}$ in a $5 \% \mathrm{CO}_{2} / 95 \%$ air atmosphere. For each experiment, $3 \times 10^{5}$ cells were seeded in $1 \mathrm{ml}$ of fresh medium in a 24-well plate and incubated with or without chemicals for the indicated time. For the cytotoxicity study, the cells were treated with $\beta$-elemonic acid during the exponential cell growth phase.

Cytotoxicity assay. The general viability of human NSCLC A549 cells treated with or without $\beta$-elemonic acid was determined using the MTT [3-(4,5-dimethylthiazol-2-yl)-2,5-diphenyl tetrazolium bromide] method (23). The MTT was dissolved in phosphate-buffered saline (PBS) at a concentration of $5 \mathrm{mg} / \mathrm{ml}$ and filtered. From the stock solution, $100 \mu \mathrm{l}$ per $1 \mathrm{ml}$ of medium was added to each well. The plates were incubated at $37^{\circ} \mathrm{C}$ for $1 \mathrm{~h}$ with gentle agitation. After the reaction with MTT, the medium was replaced with $1 \mathrm{ml}$ of pure DMSO for color development, and the 24-well plate was read by an enzyme-linked immunosorbent assay (ELISA) reader at $570 \mathrm{~nm}$ to obtain absorbance density values to determine the cell viability. The viable cells after MTT treatment produced a dark blue formazan product, whereas no such staining formed in the dead cells.

Apoptotic assay by Annexin $V$ staining. The apoptotic status of the cells was evaluated by measuring the exposure of phosphatidylserine on the cell membranes, using apoptosis detection kits (R\&D systems). Cells were harvested and resuspended in a staining solution containing PI $(50 \mathrm{mg} / \mathrm{ml})$ and Annexin V-FITC $(25 \mathrm{mg} / \mathrm{ml})$ for $15 \mathrm{~min}$ at room temperature in the dark. The cell apoptosis was examined under a fluorescence microscopic system (Olympus TX 4).

DNA content and cell cycle analysis. Human A549 cells were collected and rinsed with PBS, after being cultured with 0 , 1,3 , or $10 \mu \mathrm{M} \beta$-elemonic acid for $24 \mathrm{~h}$ and suspended in $75 \%$ ethanol at $-20^{\circ} \mathrm{C}$ overnight. The fixed cells were centrifuged at 1,200 $\mathrm{x} g$ and washed twice with PBS. To detect 

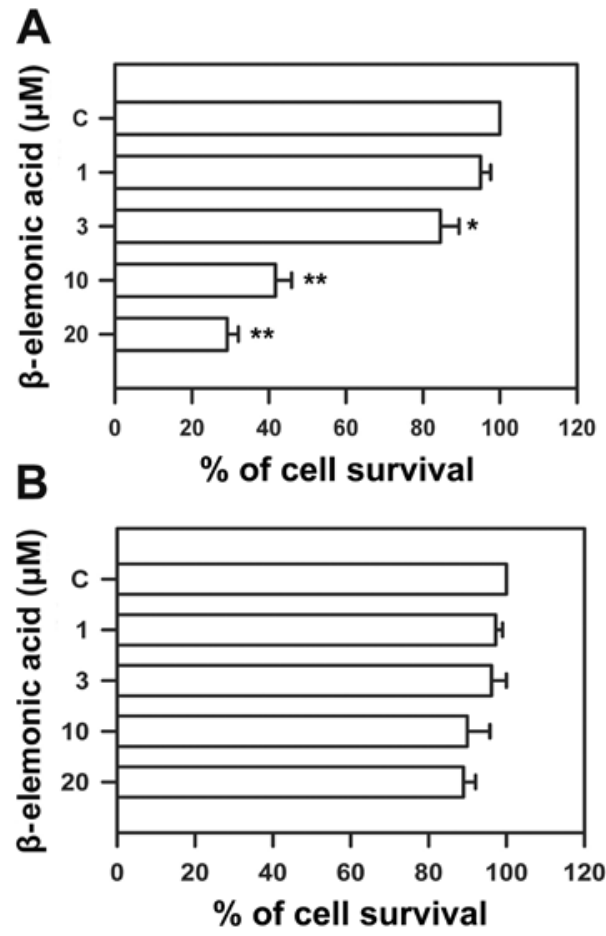

Figure 2. Cytotoxicity of $\beta$-elemonic acid on human NSCLC A549 (A) and normal epithelial WI-38 (B) cells. Human NSCLC A549 cells were incubated with $0,1,3,10$, or $20 \mu \mathrm{M}$ of $\beta$-elemonic acid for $24 \mathrm{~h}$. At the end of the incubation, the cell survival rate was determined by the MTT assay as described in Materials and methods. The cytotoxicity is expressed as the percentage of cell survival compared with the control. Data are expressed as the mean \pm SEM of $4-5$ determinations, ${ }^{*} \mathrm{P}<0.01$ and ${ }^{* *} \mathrm{P}<0.001$.

DNA content, the cells were contained in the dark with PI $50 \mathrm{mg} / 1$ and $0.1 \%$ RNase A in $400 \mu 1 \mathrm{PBS}$ at $25^{\circ} \mathrm{C}$ for $30 \mathrm{~min}$. Stained cells were analyzed on FACSort (Becton Dickinson, San Diego, CA, USA). The percentage of apoptotic cells was determined using CellQuest software.

Measurement of reactive oxygen species (ROS). The cells were incubated in the absence or presence $(1,3$, or $10 \mu \mathrm{M})$ of $\beta$-elemonic acid for $24 \mathrm{~h}$. Thirty minutes before terminating the incubation period, DCF-DA (final concentration of $10 \mathrm{mM}$ ) was added to the cells and incubated for the last $30 \mathrm{~min}$ at $37^{\circ} \mathrm{C}$. The cells were subsequently harvested to detect ROS accumulation by using the ELISA immunoassay method.

Western blot analysis. After exposure to the indicated concentrations of $\beta$-elemonic acid, human NSCLC A549 cells were washed with cold PBS. Whole cell extracts were prepared by incubating the cells with a cold lysis buffer $(20 \mathrm{mM}$ Tris- $\mathrm{HCl}$; $\mathrm{pH} 7.5,150 \mathrm{mM} \mathrm{NaCl}, 1 \mathrm{mM}$ EDTA, 1 mM EGTA, $1 \%$ Triton, $2.5 \mathrm{mM}$ sodium pyrophosphate, $1 \mathrm{mM} \beta$-glycerophosphate, $1 \mathrm{mM} \mathrm{Na} \mathrm{VO}_{4}, 1 \mu \mathrm{g} / \mathrm{ml}$ of leupeptin and $1 \mathrm{mM}$ PMSF). The protein content of the lysates was determined using the detergent-compatible colorimetric (DC) protein assay kit (Bio-Rad, Berkeley, CA, USA). The cell lysates ( $25 \mu \mathrm{g}$ of protein/lane) were electrophoresed on $12 \%$ SDS-polyacrylamide gels. The cellular proteins were subsequently transferred to polyvinylidene difluoride (PVDF) membranes by electroblotting for $2 \mathrm{~h}$ and western blot analysis was conducted as previously

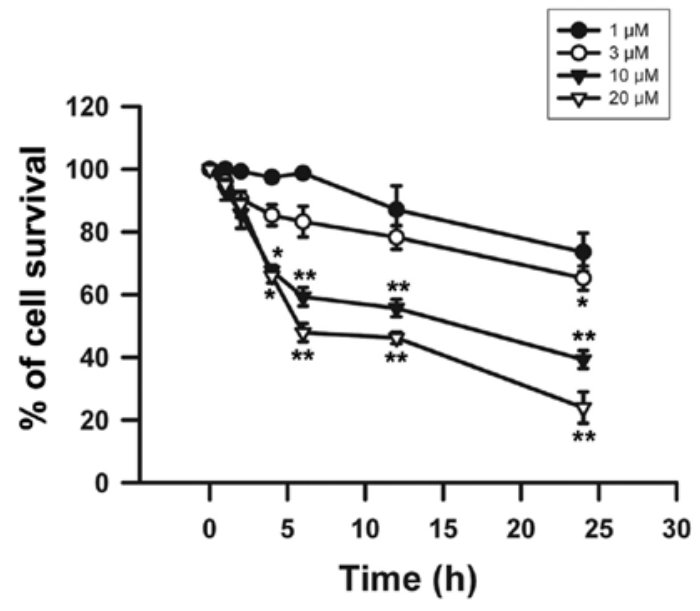

Figure 3. Time course of the cytotoxic effect of $\beta$-elemonic acid in human NSCLC A549 cells. Human NSCLC A549 cells were incubated with $\beta$-elemonic acid $(1,3,10$ or $20 \mu \mathrm{M})$ for different time periods. At the end of the incubation, the cell survival rate was determined by MTT assay as described in Materials and methods. The cytotoxicity is expressed as the percentage of cell survival compared with the controls. The data are expressed as the mean \pm SEM of 4-5 determinations, ${ }^{*} \mathrm{P}<0.01$ and ${ }^{* *} \mathrm{P}<0.001$.

described (24). The protein levels were visualized using an enhanced chemiluminescence detection kit (Amersham Pharmacia Biotech, Piscataway, NJ, USA).

Statistical analysis. All experimental data are presented as the mean and standard error (mean \pm SEM) from four to five experiments. The statistical analysis of data was performed using a one-way analysis of variance (ANOVA), followed by the Schefft test and $\mathrm{P}<0.05$ was considered to indicate a statistically significant difference.

\section{Results}

$\beta$-elemonic acid induces cell cytotoxicity in A549 cells but not in normal lung WI-38 cells. Human NSCLC A549 cells and normal epithelial WI-38 cells were treated with various doses of $\beta$-elemonic acid, and cell viability was measured using the MTT assay to assess the cytotoxicity of $\beta$-elemonic acid. $\beta$-elemonic acid exerted potent cytotoxic effects on human NSCLC A549 cells in a dose-dependent manner (Fig. 2A). The $\mathrm{IC}_{50}$ value following a 24 -h exposure to $\beta$-elemonic acid was $6.92 \pm 0.83 \mu \mathrm{M}$. The same dose as that for treating the NSCLC A549 cells did not appear to exert inhibitory effects on human WI-38 cells (Fig. 2B). In addition, $\beta$-elemonic acid also exhibited a decreased cell survival rate in the A549 cells in a time-dependent manner at each of the treatment doses tested (Fig. 3). Significant cell death was observed at 10 and $20 \mu \mathrm{M} \beta$-elemonic acid after a 2-h treatment and sharply declined after a 6-h incubation. After a 24-h treatment with 10 and $20 \mu \mathrm{M} \beta$-elemonic acid, the cell survival rate dropped to $<40 \%$ and $30 \%$, respectively. The exposure of $\beta$-elemonic acid for $24 \mathrm{~h}$ induced a significant cytotoxic effect on A549 cells in a dose-dependent manner. Therefore, we adopted these conditions in the following experiments to investigate the mechanisms related to $\beta$-elemonic acid-induced cytotoxicity. 
A

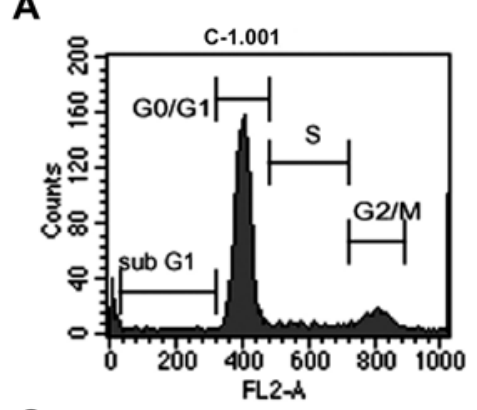

C

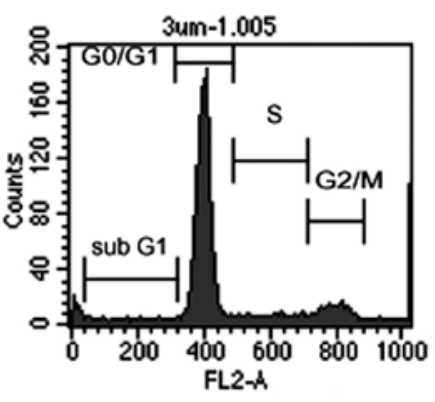

E

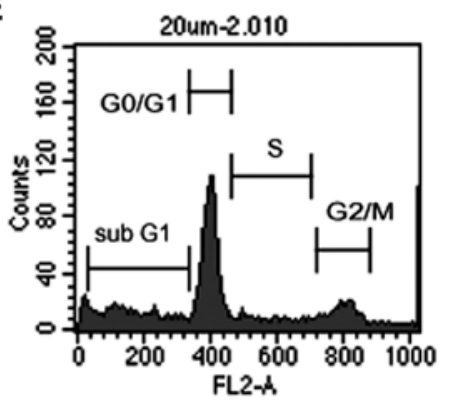

B

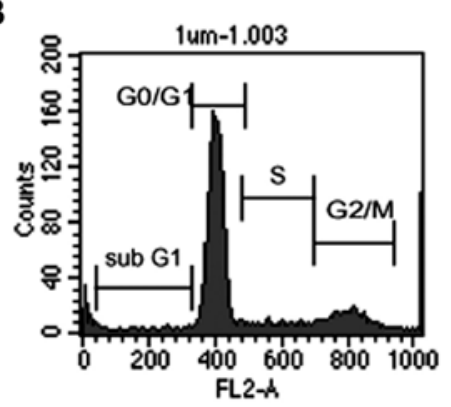

D

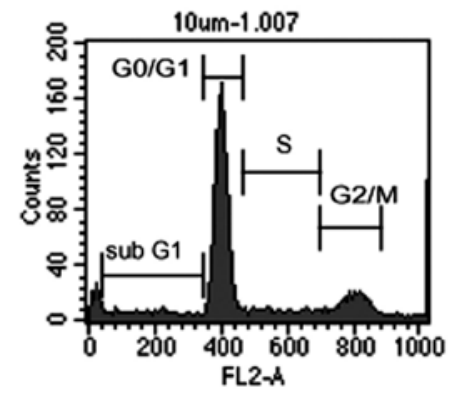

F

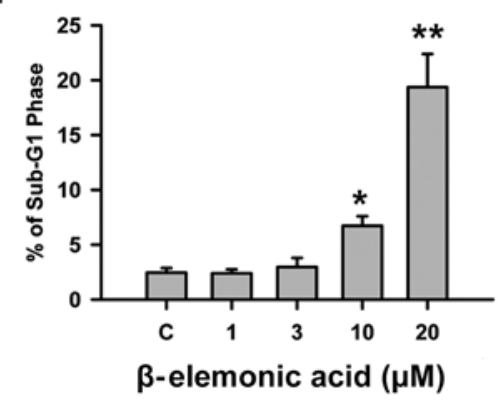

Figure 4. Evaluation of $\beta$-elemonic acid-induced apoptosis in human lung A549 cells. Human A549 cells were treated with the indicated concentrations of $\beta$-elemonic acid $(1,3,10$, or $20 \mu \mathrm{M})$ (B-E) or an equal volume of the vehicle DMSO (control) (A) and examined after $24 \mathrm{~h}$ for DNA degradation (\% of hypoploid cells) characteristic of apoptosis using hypotonic PI staining (F). The hypoploid cells have less cellular DNA content than cells typically found in the G0/G1, S or G2/M phases of the cell cycle, which causes them to retain less PI, a fluorescent DNA stain. The decreased retention of PI by the hypoploid cells shifts their fluorescence intensity leftward on the linear $\mathrm{x}$-axis of the representative histograms.

Table I. Evaluation of $\beta$-elemonic acid-induced apoptosis in human NSCLC A549 cells.

\begin{tabular}{lcccc}
\hline & \multicolumn{4}{c}{ Cell cycle phase $(\%)$} \\
\cline { 2 - 4 }$\beta$-elemonic acid $(\mu \mathrm{M})$ & Sub-G1 & $\mathrm{G} 0 / \mathrm{G} 1$ & $\mathrm{~S}$ & $\mathrm{G} 2 / \mathrm{M}$ \\
\hline $\mathrm{C}$ & $2.45 \pm 0.42$ & $76.99 \pm 0.60$ & $6.92 \pm 0.43$ & $13.48 \pm 0.17$ \\
1 & $2.39 \pm 0.36$ & $76.04 \pm 0.76$ & $7.78 \pm 0.20$ & $13.53 \pm 0.39$ \\
3 & $2.96 \pm 0.84$ & $79.21 \pm 0.29$ & $6.40 \pm 0.16$ & $12.05 \pm 0.45$ \\
10 & $6.72 \pm 0.87$ & $69.64 \pm 1.40$ & $8.81 \pm 0.33$ & $14.84 \pm 0.35$ \\
20 & $19.37 \pm 3.02^{\mathrm{a}}$ & $58.10 \pm 3.51$ & $10.33 \pm 0.36$ & $15.33 \pm 0.70$ \\
\hline
\end{tabular}

Human A549 cells were treated with the indicated concentrations of $\beta$-elemonic acid $(1,3,10$, or $20 \mu \mathrm{mol} / \mathrm{l})$ or an equal volume of the vehicle DMSO (C, control) and examined after $24 \mathrm{~h}$ for DNA degradation (\% of hypoploid cells) characteristic of apoptosis using hypotonic PI staining. The hypoploid cells have less cellular DNA content than cells typically found in the G0/G1, S or G2/M phases of the cell cycle, which causes them to retain less PI, a fluorescent DNA stain. The decreased retention of PI by the hypoploid cells shifts their fluorescence intensity leftward on the linear $\mathrm{x}$-axis of the representative histograms (Fig. 4). ${ }^{\mathrm{a}} \mathrm{P}<0.001$.

Characterization of $\beta$-elemonic acid-induced apoptotic cell death in human NSCLC A549 cells. To characterize whether $\beta$-elemonic acid-induced cell death was caused by apoptosis, we examined several hallmarks of apoptosis; namely, early apoptosis and DNA fragmentation, using Annexin V staining or flow cytometric analysis. Fig. 4 illustrates the change in 


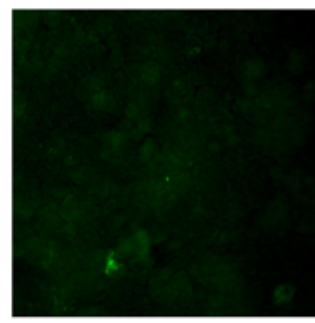

C

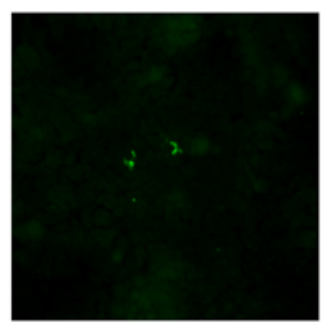

1

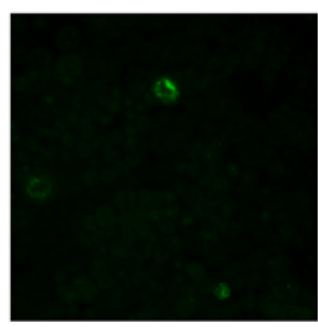

3

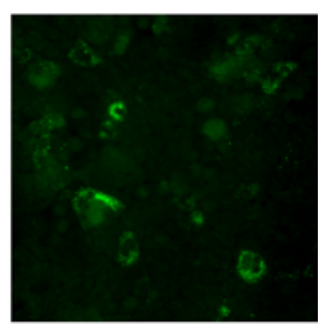

10

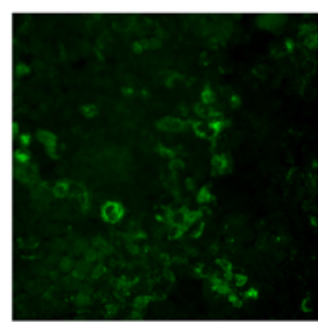

20

\section{$\beta$-elemonic acid $(\mu \mathrm{M})$}

Figure 5. Annexin V binding in A549 cells. Human A549 lung cancer cells were treated with vehicle and $\beta$-elemonic acid (1, 3 , 10 or $20 \mu \mathrm{M})$ for $24 \mathrm{~h}$ and then stained with FITC-Annexin V and examined by fluorescence microscopy.

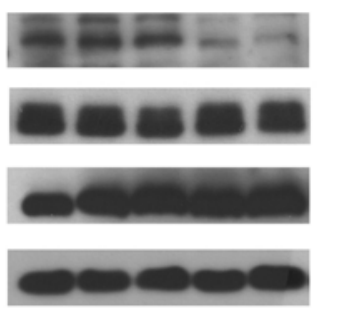

\section{P-Bcl-2 (ser70)}

Bcl-XL

Bax

$\beta$-actin

C $1 \quad 3 \quad 1020$

$\beta$-elemonic acid $(\mu \mathrm{M})$
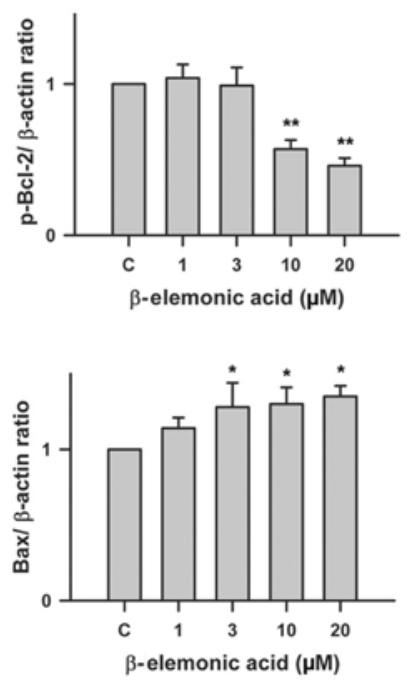

ment dose increased, the percentage of cells in the hypoploid (sub-G1) phase increased accordingly. Following treatment with 10 and $20 \mu \mathrm{M} \beta$-elemonic acid for $24 \mathrm{~h}$, the percentage of sub-G1 phase cells increased by $6.72 \pm 0.87$ and $19.37 \pm 3.02 \%$, respectively (Fig. 4D and E; Table I). The number of apoptotic cells, which carry fragmented nuclear particles, was significantly increased in the $\beta$-elemonic acid-treated cells in a dose-dependent manner (Fig. 4F).

In addition, treatment with $20 \mu \mathrm{M} \beta$-elemonic acid resulted in a cell percentage of $58.01 \pm 3.51 \%$ in the $\mathrm{G} 0 / \mathrm{G} 1$ phase, compared with $76.99 \pm 0.60 \%$ in the vehicle-treated cells (Table I). The percentage of cells in the $\mathrm{S}$ phase increased from $6.92 \pm 0.43 \%$ in the vehicle-treated cells to $10.33 \pm 0.36 \%$ in the cells treated with $20 \mu \mathrm{M} \beta$-elemonic acid after $24 \mathrm{~h}$ of exposure. We also observed a slight increase in the proportion of cells in the $\mathrm{G} 2 / \mathrm{M}$ phase from $13.48 \pm 0.17 \%$ in the vehicle-treated cells to $15.33 \pm 0.70 \%$ in the cells treated with $20 \mu \mathrm{M} \beta$-elemonic acid after $24 \mathrm{~h}$ of exposure, but with no significant difference. These results demonstrated that $\beta$-elemonic acid induced human NSCLC A549 cell cytotoxicity by inducing apoptosis.

Exposure of phosphatidylserine on the cell surface is an early event in the onset of apoptosis, which has strong binding affinity for Annexin $\mathrm{V}$ in the presence of calcium. Human NSCLC A549 cells were incubated with various concentrations of $\beta$-elemonic acid, and the cells were stained with Annexin V-FITC to assess the apoptotic population. The fluorescence examination revealed that the $\beta$-elemonic acid-treated cells showed early apoptotic morphological change and increased fluorescence intensity (Fig. 5). The induction of early apoptosis was significantly increased in the $\beta$-elemonic acid-treated cells in a dose-dependent manner. Thus, $\beta$-elemonic acid induced human NSCLC A549 cell death via an apoptotic pathway.

Regulation of Bcl-2 family proteins in $\beta$-elemonic acid-treated non-small cell lung cancer cells. To determine whether Bcl-2 family proteins are modulated in the $\beta$-elemonic acid-induced apoptosis in human A549 cells, we examined the expression of several members of the Bcl-2 family proteins using western blot analysis. Fig. 6 indicates that the exposure of human A549 cells to $1-20 \mu \mathrm{M} \beta$-elemonic acid resulted in a significant

decrease in Bcl-2 protein expression, and a marked increase in mately the same percentage of hypoploid cells observed in the DMSO-treated control (Fig. 4A-C and Table I). As the treat-
DNA content distribution in cells treated with $\beta$-elemonic acid for $24 \mathrm{~h}$. We examined these cells for degraded DNA characteristic of apoptosis, indicated by hypoploid DNA (sub-G1 phase) content, using PI staining. Exposure of human NSCLC A549 cells to 0 or $3 \mu \mathrm{M} \beta$-elemonic acid promoted approxi- 

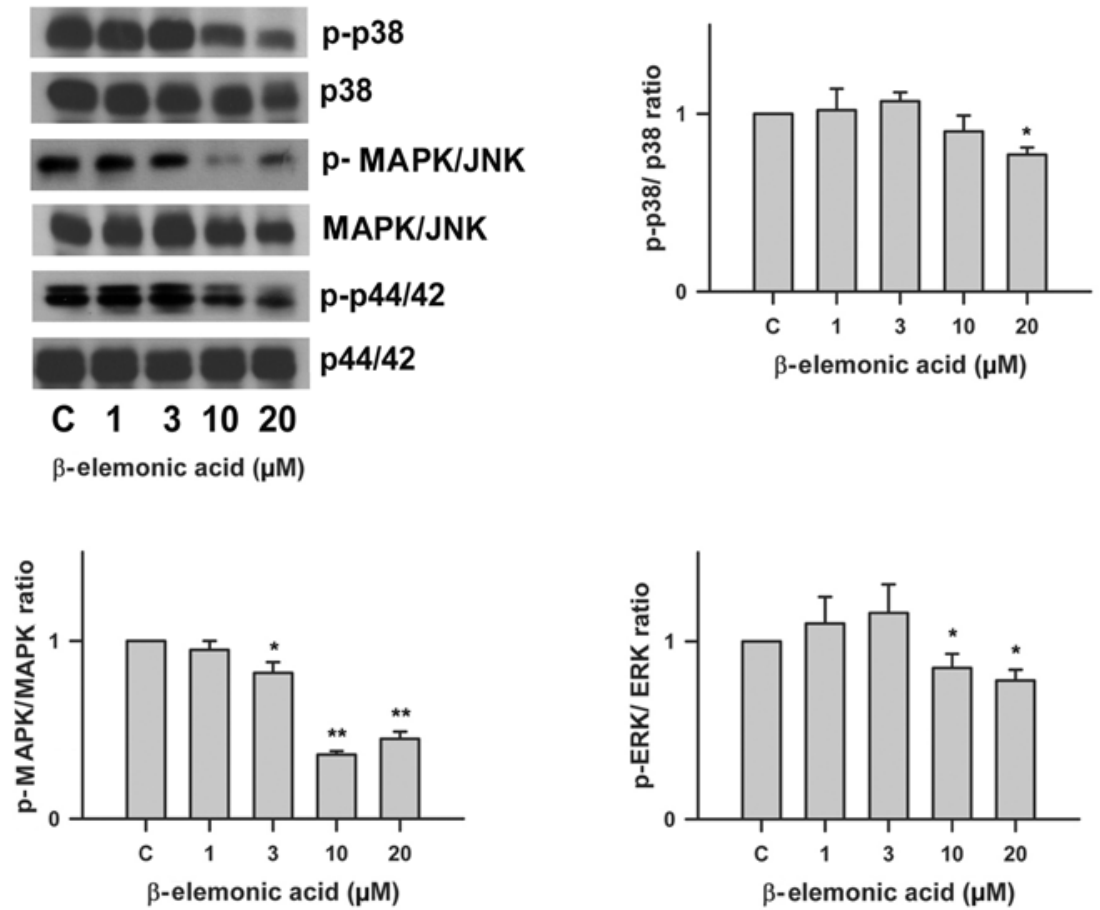

Figure 7. Effects of $\beta$-elemonic acid on p42/44, MAPK/JNK and p38 MAPK signaling pathway in A549 cells. Human A549 cells were treated with 1-20 $\mu \mathrm{M}$ $\beta$-elemonic acid for $24 \mathrm{~h}$, and $\mathrm{p} 42 / 44$, MAPK/JNK, 38 MAPK phosphorylation was assessed by immunoblotting with an antibody specific for phosphorylated p42/44, MAPK/JNK, p38 MAPK (p-p42/44, p-MAPK/JNK, and p-p38, respectively). Quantification of p-p38/p38 ratio (right upper panel), p-MAPK/MAPK ratio (left lower panel), and p-ERK/ERK ratio (right lower panel) are also represent. Equal loading in each lane is shown by the similar intensities of p42/44, MAPK/JNK, p38 MAPK (p42/44, MAPK/JNK and p38, respectively). The data are representative of three independent experiments.

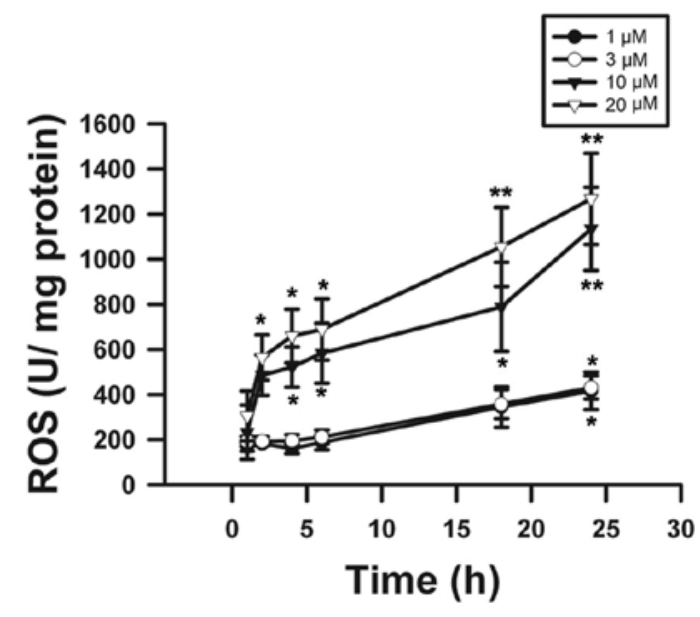

Figure 8. Effects of $\beta$-elemonic acid on ROS generation were determined after $0-24$ h of incubation with $(1,3,10$ or $20 \mu \mathrm{M}) \beta$-elemonic acid using the DCF-DA assay.

Bax protein expression. However, the level of $\mathrm{Bcl}-\mathrm{X}_{\mathrm{L}}$ protein was not affected by $\beta$-elemonic acid treatment.

Regulation of the MAPK signaling pathway in $\beta$-elemonic acid-treated A549 lung cancer cells. Using western blot analysis, we investigated the effect of $\beta$-elemonic acid on the phosphorylation of $\mathrm{p} 42 / 44$, MAPK/JNK and p38 MAP kinase. $\beta$-elemonic acid inhibited phosphorylation of $\mathrm{p} 42 / 44$, MAPK/JNK and p38 in the A549 cells (Fig. 7) in vitro. The phosphorylation of $\mathrm{p} 42 / 44 \mathrm{MAP}, \mathrm{MAPK} / \mathrm{JNK}$ and p38kinase were inhibited by $10 \mu \mathrm{M} \beta$-elemonic acid.
Effects on ROS activity and COX-2 protein expression by $\beta$-elemonic acid in human A549 lung cancer cells. The results obtained in the present study provided profound evidence that $\beta$-elemonic acid exhibited oxidative injury in A549 cells. Using the DCFH-DA assay, the results revealed that $\beta$-elemonic acid induced ROS levels (Fig. 8). We examined the effects of $\beta$-elemonic acid on COX-2 expression in A549 cells, and the expression of COX-2 proteins was examined using western blot analysis. Fig. 9 indicates that the exposure of human lung A549 cells to $1-20 \mu \mathrm{M} \beta$-elemonic acid resulted in a marked increase in COX-2 expression. COX-2 protein was modulated in the $\beta$-elemonic acid-induced apoptosis in human lung A549 cells.

\section{Discussion}

We demonstrated that $\beta$-elemonic acid strongly inhibited the growth of human NSCLC A549 cells. This is a pioneering study of $\beta$-elemonic acid-induced cell cytotoxicity in human lung cancer cells. We observed that $\beta$-elemonic acid exerted no effect on the growth of human normal epithelial WI-38 cells, consistent with data showing that $\beta$-elemonic acid exerts a growth inhibitory effect on cancer cells, but not on normal cells. Therefore, $\beta$-elemonic acid is an excellent candidate for human NSCLC therapy without toxicity for normal cells.

Our results revealed that human A549 cells treated with $\beta$-elemonic acid exhibited characteristic morphological features of apoptosis, such as membrane shrinkage and chromosomal condensation. The hypothesis that $\beta$-elemonic acid-treated cells undergo apoptosis rather than necrosis was 
A

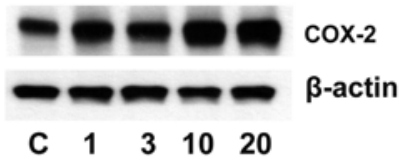

$\beta$-elemonic acid $(\mu \mathrm{M})$

B

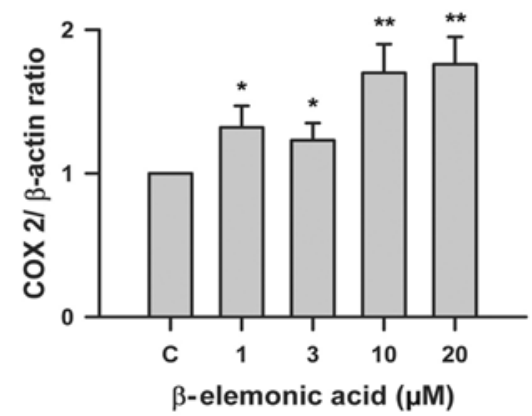

Figure 9. Expression of COX-2 protein in $\beta$-elemonic acid-treated human NSCLC A549 cells. Human NSCLC A549 cells were treated with 0-20 $\mu \mathrm{M}$ $\beta$-elemonic acid for $24 \mathrm{~h}$. After the treatment, cell lysates were extracted, and the levels of COX-2 protein were analyzed by western blot analysis.

further supported by the results from the cell cycle analysis. The proportion of hypoploid cells (sub-G1) was markedly increased after $\beta$-elemonic acid treatment. These results support the finding that $\beta$-elemonic acid induces cell death via an apoptotic pathway.

Cytotoxicity disrupts the cell cycle progression followed by an accumulation of cells in one or more cell cycle phases. An accumulation of human A549 cells at the S phase occurred in a concentration-dependent manner after treatment of the cells with $20 \mu \mathrm{M} \beta$-elemonic acid after $24 \mathrm{~h}$ of exposure. These results demonstrated that $\beta$-elemonic acid induced $S$ phase arrest in the cell cycle progression in human NSCLC A549 cells, and strongly implies impaired mitosis due to arrest in the $\mathrm{S}$ phase. This cell cycle behavior after exposure to $\beta$-elemonic acid was relatively similar to the dictamnine cytotoxicity effect on A549 cells (25). The cell cycle disruption might partially be explained by the checkpoint response from DNA damage or other mechanisms that require further investigation.

Human NSCLC A549 cells treated with $\beta$-elemonic acid exhibited characteristic morphological features of apoptosis, such as membrane shrinkage and chromosomal condensation. Apoptosis is also accompanied by a loss of membrane phospholipid asymmetry, resulting in phosphatidylserine exposure at the cell surface. Phosphatidylserine expression at the cell surface plays a crucial role in the recognition and removal of apoptotic cells by macrophages (26). The hypothesis that $\beta$-elemonic acid-treated cells undergo apoptosis rather than necrosis was further supported by the result from the binding of fluorescein isothiocyanate-labeled Annexin V to phosphatidylserine. Exposure of phosphatidylserine on the cell surface is an early event in the onset of apoptosis, which has strong binding affinity with Annexin $\mathrm{V}$ in the presence of calcium. In our results, the number of Annexin V-positive human NSCLC A549 cells was markedly increased after $\beta$-elemonic acid treatment in a dose-dependent manner. Therefore, we inferred that $\beta$-elemonic acid induced cell death via an apoptotic pathway.

Several mechanisms for activating apoptosis under various physiological or pathological conditions in cells have been proposed and studied intensively (27). Numerous factors, such as the expression of Bcl-2 family proteins and the MAPK signaling pathway, have been suggested to play an essential role in the apoptotic process in cancer cells. The Bcl-2 family of proteins controls a critical step in commitment to apoptosis by regulating the permeability of the mitochondrial outer membrane. The family is divided into three classes: i) the BH3 proteins that sense cellular stress and activate, ii) the executioner proteins Bax or Bak that oligomerize and break down the mitochondrial outer membrane potential and iii) the anti-apoptotic members such as Bcl-2 that impede the overall process by inhibiting both $\mathrm{BH} 3$ and executioner proteins (28). As evidenced by western blot analysis, our results demonstrated that $\beta$-elemonic acid-mediated apoptosis was involved in $\mathrm{Bcl}-2$ downregulation rather than $\mathrm{Bcl}_{\mathrm{L}}$ to execute $\mathrm{Bax}$ oligomerization. Activated Bax enters the mitochondrial outer membrane, forming oligomers that lead to membrane poration, release of cytochrome $c$ and apoptosis.

The MAPKs are a family of kinases that transduce signals from the cell membrane to the nucleus in response to various insults. MAPKs are serine/threonine kinases that phosphorylate substrates that regulate gene expression, mitosis, proliferation, motility, metabolism and programmed apoptotic death (19). ERK1 and ERK2 are well-characterized MAPKs activated in response to growth stimuli. Both JNKs and p38-MAPK are simultaneously activated in response to a wide range of cellular and environmental stresses, such as changes in either osmolarity or metabolism, DNA damage, heat shock, ischemia, inflammatory cytokines, or oxidative stress (29). In our experiment, presented in Fig. 7, $\beta$-elemonic acid inhibited phosphorylation of these MAPK pathways in a dose-dependent manner and the difference was significant at a concentration of $10 \mu \mathrm{M}$.

Numerous in vitro studies have revealed that cancer cells exhibit increased intrinsic ROS stress, increased metabolic activity and mitochondrial malfunction. Because the mitochondrial respiratory chain (electron transport complexes) is a primary source of cellular ROS generation, the vulnerability of the mitochondrial DNA to ROS-mediated damage appears to be a mechanism to amplify ROS stress in cancer cells (30). To assess the cytotoxicity produced by $\beta$-elemonic acid on NSCLC A549 cells, we investigated the role of oxidative stress in ROS generation. The effect of $\beta$-elemonic acid on oxidative stress was analyzed using various concentrations at distinct incubation periods. The time-dependent increase in ROS formation presented in Fig. 8 suggests that ROS generation is a crucial mechanism of action, which might contribute to the cytotoxicity of $\beta$-elemonic acid in NSCLC A549 cells. Generation of intracellular ROS depletes glutathione (GSH), reduces superoxide dismutase (SOD) enzyme activity and increases lipid peroxidation in cells, which inevitably results in cell death.

The NSCLC A549 cells possess the capacity of expressing COX-2 activity during tumorigenesis by enhancing the expression of angiogenic chemokines CXCL8 and CXCL5 (31). COX-2 is a downstream target of PPAR $\gamma$ and 
its correlation between NSCLC A549 cells has emerged in numerous studies (32). Transcriptional upregulation of COX-2 activity was also observed in an interleukin-1 $\beta$-treated A549 cell line (33). Consequently, strong evidence supports the positive correlation between enhanced COX-2 activity and tumor growth. The western blot analysis presented in Fig. 9 revealed that $\beta$-elemonic acid increased COX-2 activity in the NSCLC A549 cells. Despite the unexpected result from our study, we deduced diverse COX-2 activity responses after various stimuli were applied to NSCLC A549 cells.

In summary, our findings suggest that treatment with the anticancer drug, $\beta$-elemonic acid, caused cell death through apoptosis rather than necrosis, inducing cell cycle arrest at the $\mathrm{S}$ phase and apoptosis via the MAPK signaling pathway in NSCLC cells. Our findings provide insight into the molecular action of $\beta$-elemonic acid involving COX-2 activity and ROS generation in A549 cells and provides clues for understanding the biological activities of $\beta$-elemonic acid for the treatment of NSCLC.

\section{Acknowledgements}

The present study was supported by grant TCPH97-002 from the Taipei County Hospital and grant CTH97-1-2A34 from the Catholic Cardinal Tien Hospital. We also thank C.F. Yang for her excellent technical assistance.

\section{References}

1. Anonymous: Analysis in cancer incidence and mortality Taiwan. Epidermal Bull, pp381-391, 1999 (In Chinese).

2. Sandler AB, Nemunaitis J, Denham C, von Pawel J, Cormier Y, Gatzemeier U, Mattson K, Manegold C, Palmer MC, Gregor A, et al: Phase III trial of gemcitabine plus cisplatin versus cisplatin alone in patients with locally advanced or metastatic non-small-cell lung cancer. J Clin Oncol 18: 122-130, 2000

3. Bonomi P, Kim K, Fairclough D, Cella D, Kugler J, Rowinsky E, Jiroutek M and Johnson D: Comparison of survival and quality of life in advanced non-small-cell lung cancer patients treated with two dose levels of paclitaxel combined with cisplatin versus etoposide with cisplatin: Results of an Eastern Cooperative Oncology Group trial. J Clin Oncol 18: 623-631, 2000.

4. Fisher DE: Apoptosis in cancer therapy: Crossing the threshold. Cell 78: 539-542, 1994

5. Kaufmann SH and Earnshaw WC: Induction of apoptosis by cancer chemotherapy. Exp Cell Res 256: 42-49, 2000.

6. Medema JP, Scaffidi C, Kischkel FC, Shevchenko A, Mann M, Krammer PH and Peter ME: FLICE is activated by association with the CD95 death-inducing signaling complex (DISC). EMBO J 16: 2794-2804, 1997.

7. Adams JM and Cory S: The Bcl-2 protein family: Arbiters of cell survival. Science 281: 1322-1326, 1998.

8. Antonsson B and Martinou JC: The Bcl-2 protein family. Exp Cell Res 256: 50-57, 2000.

9. Kausch I and Böhle A: Antisense oligonucleotide therapy in urology. J Urol 168: 239-247, 2002.

10. McDonnell TJ, Beham A, Sarkiss M, Andersen MM and Lo P: Importance of the Bcl-2 family in cell death regulation. Experientia 52: 1008-1017, 1996.

11. Farrow SN and Brown R: New members of the Bcl-2 family and their protein partners. Curr Opin Genet Dev 6: 45-49, 1996.

12. Schmitt E, Sané AT, Steyaert A, Cimoli G and Bertrand R: The Bcl-xL and Bax-alpha control points: Modulation of apoptosis induced by cancer chemotherapy and relation to TPCK-sensitive protease and caspase activation. Biochem Cell Biol 75: 301-314, 1997.
13. Meade EA, McIntyre TM, Zimmerman GA and Prescott SM: Peroxisome proliferators enhance cyclooxygenase-2 expression in epithelial cells. J Biol Chem 274: 8328-8334, 1999.

14. Pontsler AV, St Hilaire A, Marathe GK, Zimmerman GA and McIntyre TM: Cyclooxygenase-2 is induced in monocytes by peroxisome proliferator activated receptor gamma and oxidized alkyl phospholipids from oxidized low density lipoprotein. J Biol Chem 277: 13029-13036, 2002.

15. Kalajdzic T, Faour WH, He QW, Fahmi H, Martel-Pelletier J, Pelletier JP and Di Battista JA: Nimesulide, a preferential cyclooxygenase 2 inhibitor, suppresses peroxisome proliferator-activated receptor induction of cyclooxygenase 2 gene expression in human synovial fibroblasts: Evidence for receptor antagonism. Arthritis Rheum 46: 494-506, 2002.

16. Mitchell JA, Belvisi MG, Akarasereenont P, Robbins RA, Kwon OJ, Croxtall J, Barnes PJ and Vane JR: Induction of cyclo-oxygenase- 2 by cytokines in human pulmonary epithelial cells: Regulation by dexamethasone. Br J Pharmacol 113: 1008-1014, 1994

17. Chen CC, Sun YT, Chen JJ and Chiu KT: TNF-alpha-induced cyclooxygenase-2 expression in human lung epithelial cells: Involvement of the phospholipase $\mathrm{C}$-gamma 2, protein kinase $\mathrm{C}$-alpha, tyrosine kinase, NF-kappa B-inducing kinase, and I-kappa B kinase 1/2 pathway. J Immunol 165: 2719-2728, 2000.

18. Davis RJ: Signal transduction by the JNK group of MAP kinases. Cell 103: 239-252, 2000.

19. Chang L and Karin M: Mammalian MAP kinase signalling cascades. Nature 410: 37-40, 2001.

20. Kyriakis JM and Avruch J: Mammalian mitogen-activated protein kinase signal transduction pathways activated by stress and inflammation. Physiol Rev 81: 807-869, 2001.

21. Atta-ur-Rahman, Naz H, Fadimatou, Makhmoor T, Yasin A, Fatima N, Ngounou FN, Kimbu SF, Sondengam BL and Choudhary MI: Bioactive constituents from Boswellia papyrifera. J Nat Prod 68: 189-193, 2005.

22. Lee HJ and Soliman MR: Anti-inflammatory steroids without pituitary-adrenal suppression. Science 215: 989-991, 1982.

23. Mosmann T: Rapid colorimetric assay for cellular growth and survival: Application to proliferation and cytotoxicity assays. J Immunol Methods 65: 55-63, 1983.

24. Jow GM, Wu YC, Guh JH and Teng CM: Armepavine oxalate induces cell death on CCRF-CEM leukemia cell line through an apoptotic pathway. Life Sci 75: 549-557, 2004.

25. An FF, Liu YC, Zhang WW and Liang L: Dihydroartemisinine enhances dictamnine-induced apoptosis via a caspase dependent pathway in human lung adenocarcinoma A549 cells. Asian Pac J Cancer Prev 14: 5895-5900, 2013.

26. Koopman G, Reutelingsperger CP, Kuijten GA, Keehnen RM, Pals ST and van Oers MH: Annexin V for flow cytometric detection of phosphatidylserine expression on $\mathrm{B}$ cells undergoing apoptosis. Blood 84: 1415-1420, 1994.

27. Vaux DL and Korsmeyer SJ: Cell death in development. Cell 96 245-254, 1999.

28. Shamas-Din A, Kale J, Leber B and Andrews DW: Mechanisms of action of Bcl-2 family proteins. Cold Spring Harb Perspect Biol 5: a008714, 2013.

29. Wada T and Penninger JM: Mitogen-activated protein kinases in apoptosis regulation. Oncogene 23: 2838-2849, 2004.

30. Pelicano H, Carney D and Huang P: ROS stress in cancer cells and therapeutic implications. Drug Resist Updat 7: 97-110, 2004.

31. Põld M, Zhu LX, Sharma S, Burdick MD, Lin Y, Lee PP, Põld A, LuoJ,KrysanK,DohadwalaM,etal:Cyclooxygenase-2-dependent expression of angiogenic CXC chemokines ENA-78/CXC Ligand (CXCL) 5 and interleukin-8/CXCL8 in human non-small cell lung cancer. Cancer Res 64: 1853-1860, 2004.

32. Bakhle YS: COX-2 and cancer: A new approach to an old problem. Br J Pharmacol 134: 1137-1150, 2001.

33. Newton R, Kuitert LM, Bergmann M, Adcock IM and Barnes PJ: Evidence for involvement of NF-kappaB in the transcriptional control of COX-2 gene expression by IL-1beta. Biochem Biophys Res Commun 237: 28-32, 1997. 